\title{
Uso de jogos e análise de erros em resoluções de equações: uma experiência com alunos de 6 série do Ensino Fundamental
}

Angelita Uberti

Helena Noronha Cury

\section{Resumo}

Neste artigo, é apresentado relato parcial de uma investigação sobre o uso de jogos como recurso para o ensino e a aprendizagem de equações, sistemas de equações e inequações de 19 grau. $O$ trabalho foi desenvolvido com uma turma de 24 alunos de 60 série do Ensino Fundamental, de uma escola municipal do interior do Rio Grande do Sul. A pesquisa é de caráter qualitativo e nela foram empregados, como instrumentos, um teste e observações de sala de aula. Apresentamos a análise dos erros cometidos pelos alunos e o relato sobre a construção e aplicação de um jogo para superação das dificuldades apresentadas pelos estudantes na resolução de equações. Ao final, sugerimos a reaplicação da experiência por professores de Ensino Fundamental, em outras turmas ou com outros conteúdos, proporcionando subsídios para o uso da análise de erros e de jogos.

Palavras-chave: jogos, análise de erros, equações, Ensino Fundamental.

\footnotetext{
Abstract

Use of games and error analysis in solving equations: an experiment with $6^{\text {th }}$ year students of elementary school

In this paper, we present a partial report of a research on the use of games as a resource for teaching and learning equations, systems of equations and inequalities of $1^{\text {rst }}$ degree. The work was developed with a class of 24 students in a $6^{\text {th }}$ grade of elementary school, on a public school in Rio Grande do Sul. In this qualitative research, tests and classroom observations were employed as tools. We present the analysis of errors made by students and report the construction and implementation of a game to overcome the difficulties presented by the students in solving equations. Finally, It is suggested the reapplication of the experiment by elementary school teachers in other classrooms or with other contents, providing
} 
subsidies for the use of error analysis and games.

Keywords: games, error analysis, equations, elementary school.

\section{Introdução}

A ideia de desenvolver uma pesquisa sobre uso de jogos surgiu da necessidade de buscar formas de despertar o interesse de uma turma de alunos pela Matemática. Nas aulas em que apenas eram empregados quadro-negro, giz, listas de exercícios e livros didáticos, havia dificuldade de fazer com que os estudantes se envolvessem nas tarefas.

Ao iniciar o projeto de dissertação em um curso de mestrado profissionalizante em ensino de Matemática, ao mesmo tempo em que enfrentava dificuldades para introduzir os conteúdos de equações, sistemas de equações e inequações nas aulas dessa turma, a primeira autora considerou a possibilidade de utilizar jogos para motivar os estudantes.

Assim, a pesquisa foi desencadeada com as seguintes indagações: a) quais as dificuldades apresentadas pelos alunos na aprendizagem de equações, inequações e sistemas de equações de 10 grau? b) quais jogos podem auxiliar a superar as dificuldades de aprendizagem desses conteúdos? Esta pesquisa foi desenvolvida, portanto, com os objetivos de analisar as dificuldades apresentadas pelos alunos em relação aos conteúdos de equações, inequações e sistemas de equações de 1으 grau e avaliar a possibilidade de usar jogos para remediar tais dificuldades.

Ao revisar a literatura sobre jogos, notamos que estabelecer uma definição para esse recurso pedagógico é um desafio, pois existe, na literatura sobre o assunto, uma grande variedade de concepções e definições sobre jogos e sobre as perspectivas diversas do seu papel no processo de ensino e aprendizagem.

Flemming e Mello (2003, p. 25) consideram que jogos são atividades que podem ser "relacionadas com o ensino, de natureza recreativa, usadas em sala de aula para obtenção de um maior rendimento no processo ensino-aprendizagem de um conteúdo específico". Para as autoras, existe uma distinção entre jogar e brincar: o jogo tem um sistema linguístico que funciona dentro de um contexto social, tem um sistema de regras, contêm, em geral, objetos bem característicos e delineados; já os brinquedos têm características culturais diversas, não possuem regras e representam os objetos reais ou uma nova representação criada durante a brincadeira.

Borin (1995) classifica os jogos em dois tipos: de treinamento e de estratégia. Os primeiros são usados, como o nome já diz, para treinar, fixar conteúdos, fórmulas ou técnicas de resolução de exercícios ou problemas. Para que não se recaia na simples memorização, facilitada pela 
repetição, Borin (1995) sugere que o professor aproveite esse tipo de jogo, também, para construir o conceito que quer fixar.

Os jogos de estratégia proporcionam a oportunidade de desenvolver o raciocínio lógico, de modo que os alunos tenham que escolher a melhor estratégia para vencer. Como há possibilidade de que o estudante cometa erros e tenha que reformular suas estratégias, esse tipo de jogo permite reformulação das hipóteses feitas, argumentação e validação, que são características de um pensamento matemático avançado.

Para Lara (2003), os jogos, quando bem elaborados, podem ser vistos como uma estratégia de ensino que poderá atingir diferentes objetivos, variando desde o simples treinamento, até a construção de um determinado conhecimento. Sintetizando sua classificação dos jogos, temos:

- Jogos de construção: são aqueles que trazem ao aluno um assunto desconhecido, de forma que, por meio da manipulação do material apresentado, ele busque um novo conhecimento para resolver os problemas propostos durante sua realização. "Jogos deste tipo permitem a construção de algumas abstrações matemáticas que, muitas vezes, são apenas transmitidas pelo/a professor/a e memorizadas sem uma real compreensão pelo/a aluno/a, prejudicando, assim, o aprendizado" (p. 24).

- Jogos de treinamento: são idealizados para auxiliar na memorização de conceitos ou técnicas operatórias, além de auxiliar no desenvolvimento de um pensamento dedutivo mais rápido. Esse tipo de jogo deve ser utilizado quando o professor percebe que alguns alunos precisam de reforço num determinado conteúdo e quer substituir as listas de exercícios.

- Jogos de aprofundamento: são aplicados depois que o aluno construiu um conhecimento sobre um determinado conteúdo, oportunizando-Ihe avançar no seu aprendizado. Podem ser utilizados em atividades de resolução de problemas, para articular os tópicos estudados ou para desafiar os alunos a um raciocínio novo.

- Jogos de estratégias: são jogos que têm como meta propiciar oportunidades para o desenvolvimento de estratégias que exijam a elaboração de hipóteses e a criação de alternativas variadas para a solução.

Além da busca aos autores que tratam dos jogos e de seus usos, também foram revisadas dissertações da área de Educação Matemática que tratam de assuntos coincidentes com os desta pesquisa, como as de Silva (2004), Jelinek (2005), Souza (2006) e Soares (2008).

O trabalho de Silva (2004), defendido na Universidade Luterana do Brasil, teve como objetivo investigar a introdução de números inteiros negativos em uma turma de 6a série, por meio de jogos. A autora propôs realizar um trabalho com os alunos, partindo sempre do jogo, da brincadeira ou da "pegadinha" e tentando chegar a uma aula participativa, ao mesmo tempo em 
que as soluções eram testadas. Seu interesse em realizar a investigação esteve ligado a jogos ou brincadeiras que pudessem ser usados no ensino da Matemática, levando o aluno a desenvolver o raciocínio lógico, a estratégia e a agilidade de cálculo.

Após as análises, a autora comentou que não avaliou o jogo pelo jogo, mas sua importância no desenvolvimento dos conteúdos de Matemática e considera que foi visível a validade do seu uso, devido ao fato de terem uma orientação clara e objetivos definidos.

A dissertação de Jelinek (2005), defendida na Pontifícia Universidade Católica do Rio Grande do Sul, teve como objetivo investigar de que forma os jogos podem ser utilizados nas aulas de Matemática e qual o paradigma dos professores em relação aos mesmos. A pesquisa é de caráter naturalístico-construtiva, uma vez que buscou analisar o uso de jogos em sala de aula, questionando um conhecimento já existente sobre o assunto e procurando esclarecer quais pressupostos os professores têm sobre os jogos: como os definem, se fazem uso dessa ferramenta, se a julgam importante.

Por meio dessa pesquisa, Jelinek (2005) verificou que a expressão "aprender brincando" realmente tem sentido, pois os jogos são atividades que envolvem descontração e alegria, o educando pode desenvolver não apenas aspectos cognitivos, mas também morais, psicológicos, afetivos, de linguagem, entre outros. Mas seu maior benefício ainda está em promover o equilíbrio da personalidade do educando, uma necessidade vital do ser humano.

A dissertação de Souza (2006), defendida na Universidade Cruzeiro do Sul, apresentou trabalho com jogos em aulas de reforço de Matemática para um grupo de alunos de 5a a 7ạ série. A intenção da autora foi de buscar formas de tornar essas aulas mais agradáveis e participativas, possibilitando a construção de hipóteses e a compreensão de alguns conceitos matemáticos.

Dos jogos utilizados por Souza (2006), alguns são existentes no mercado e outros foram construídos durante a pesquisa, para facilitar a compreensão de alguns conteúdos por parte dos alunos. Suas questões investigativas foram centradas na busca das contribuições que os jogos podem trazer para as aulas de reforço de Matemática e a autora desenvolveu uma pesquisa-açãointervenção.

Com o uso de jogos, o ensino e a aprendizagem compartilham o mesmo espaço na relação professor-aluno, conforme a opinião de Souza (2006). Também foi percebido pela autora que, ao longo das atividades com jogos pedagógicos, houve oportunidade de compreensão de conteúdos que, apesar de já trabalhados nas aulas, não haviam sido entendidos pelos alunos. Além disso, os jogos também contribuíram para despertar nos alunos o interesse pelo trabalho em grupo, o que Ihes ajudou a entender alguns assuntos ainda não compreendidos. 
A pesquisa de Soares (2008) foi defendida na Pontifícia Universidade Católica de São Paulo e teve como objetivo a investigação da potencialidade de serem reintroduzidos os números inteiros negativos, a partir de uma intervenção de ensino dirigida, em resolução de problemas, utilizando jogos como recurso didático. Também buscou verificar a compreensão dos alunos sobre as operações de adição e subtração com números inteiros, positivos e negativos, a partir do trabalho realizado com o livro didático adotado na escola onde foi realizada a pesquisa.

A investigação de Soares (2008), de caráter intervencionista, contou com alunos de três classes de sétimo ano: duas turmas constituíram o grupo experimental, com as quais houve intervenção de jogos relacionados aos números inteiros, e a terceira foi o grupo de controle, que estudou outros assuntos diferentes de números inteiros, com atividades variadas, inclusive jogos. A escolha do trabalho com jogos foi motivada pelo fato de que esses recursos fazem parte do universo infanto-juvenil de atividades, que as crianças e os adolescentes geralmente gostam de realizar fora do ambiente escolar.

Também contribui para a escolha de Soares (2008) a sua experiência na utilização de jogos em sala de aula. Após as análises, o autor pode constatar as contribuições que os jogos trouxeram para seus alunos, dentre as quais se destaca a melhoria no uso da linguagem matemática para representar e resolver corretamente as operações com números inteiros negativos.

Para o desenvolvimento desta dissertação, interessava-nos também conhecer o que está sendo estudado em dissertações e teses sobre a Álgebra e seu ensino, em cursos de PósGraduação em Educação Matemática. Muitos dos trabalhos encontrados apontam dificuldades dos alunos em aprender Álgebra, especialmente equações algébricas, apresentadas no Ensino Fundamental. Entre as pesquisas sobre ensino de equações, inequações ou sistemas de equações no Ensino Fundamental, na área de Ensino de Ciências e Matemática, encontramos os trabalhos de Freitas (2002), Melo (2007) e Damasco (2008), que abordam temas coincidentes com nosso estudo.

Freitas (2002), em dissertação defendida na Pontifícia Universidade Católica de São Paulo, analisou a compreensão dos procedimentos usados por alunos do primeiro ano do Ensino Médio de uma escola particular de São Paulo na resolução de equações do 1 으 grau. $O$ autor fez um estudo a respeito dos erros e dos procedimentos dos alunos nas resoluções de equações do 1 o grau e sua pesquisa foi realizada no turno oposto ao da aula, tendo o autor adotado entrevista semiestruturada, com os seguintes tópicos principais: o significado do sinal de igualdade, o processo de avaliação do resultado encontrado, o significado do método da transposição de termos, as diferenças sintáticas das equações.

Freitas (2002) concluiu que os erros cometidos estão relacionados tanto às equações aritméticas como às algébricas; não estão ligados a aspectos conceituais ou das técnicas, mas à inter-relação desses dois aspectos. 
Melo (2007), em dissertação defendida na Pontifícia Universidade Católica de São Paulo, teve como objetivo investigar se o tópico "inequação" estava sendo desenvolvido no Ensino Fundamental de uma cidade localizada no interior de São Paulo e, em caso positivo, de que forma o assunto era abordado. Sua fundamentação teórica foi baseada na teoria dos Registros de Representação Semiótica.

O autor elaborou um questionário que foi aplicado a 27 professores de Matemática de dez escolas do município e, além das respostas, também foi analisada parte do material didático (apostilas e livros) utilizado pelos professores participantes da pesquisa, com objetivo de confrontar algumas informações, dadas por eles, com o livro didático utilizado por cada um.

Quanto às abordagens para o ensino de Matemática, Melo (2007) observou, por meio das respostas ao questionário, que quase todos os professores, frequentemente ou sempre, explicam os conteúdos, resolvem alguns exercícios junto com os alunos e logo em seguida propõem outros como tarefa.

Sobre a forma como os professores trabalham com o tema inequações, Melo (2007) chegou à conclusão de que os docentes fazem associações com o assunto "equações" e, segundo o autor, talvez essas associações levam o aluno a resolver uma inequação com os mesmos procedimentos usados para as equações.

Damasco (2008) defendeu dissertação na Universidade Luterana do Brasil e abordou o tema equações do 1o grau, na 6ạ série do Ensino Fundamental, usando a Engenharia Didática. 0 objetivo da autora foi investigar uma metodologia adequada ao processo de ensino e aprendizagem do conteúdo de equações do 1으 grau no Ensino Fundamental. Sua hipótese de pesquisa baseou-se na ideia de que o professor de Matemática desse nível, quando desenvolve esse conteúdo na 6ạ série, não pratica uma metodologia que privilegie a compreensão dos princípios aditivo e multiplicativo, levando o aluno a não utilizá-los ao resolver uma equação do 1 으 grau na sua forma algébrica. Da mesma forma, não é trabalhada a visão geométrica de equações na 6ạ série do Ensino Fundamental.

A pesquisa de Damasco (2008) teve caráter qualitativo e o processo seguiu as quatro fases da Engenharia Didática: as análises preliminares, a concepção e análise a priori das situações, a experimentação e a análise a posteriori, com a validação. A autora iniciou seu estudo com a observação de algumas aulas de uma turma de 6a série, em seguida aplicou um questionário ao professor regente da turma, realizando, logo após, uma análise de quatro livros didáticos.

Ao organizar a sequência didática aplicada a um grupo de alunos, Damasco (2008) introduziu o conteúdo equações por meio de uma abordagem histórica do conteúdo, utilizou a resolução de problemas para introduzir o conceito de equações, aproveitou fluxogramas para o 
desenvolvimento dos conceitos de igualdade, identidade, equações do 10 grau. Para introduzir a parte algébrica de resolução de uma equação do 1 음au, a autora fez uso de um jogo, no qual o objetivo era o entendimento, por parte dos alunos, dos princípios aditivo e multiplicativo, bem como da forma de organizar a resolução de uma equação do 1 ㅇ grau com uma variável.

Com o auxílio de um software, ainda foi proposta aos alunos a resolução de equações fazendo a analogia com uma balança de dois pratos; para desenvolver a parte geométrica de representação das equações de 10 grau no sistema cartesiano de coordenadas, Damasco (2008) utilizou a metodologia da resolução de problemas. Após aplicação da sequência didática, a autora deu início à fase da validação, tendo avaliado os processos da pesquisa, bem como os resultados alcançados nas aulas realizadas durante a aplicação da sequência didática.

\section{Metodologia da pesquisa}

$\mathrm{Na}$ realização desta pesquisa, foi empregada uma abordagem qualitativa, do tipo naturalista ou de campo (FIORENTINI; LORENZATO, 2006), visto que os dados foram coletados diretamente no campo de trabalho, ou seja, nas aulas de Matemática nas quais foram propostas as questões e empregados os jogos. Como instrumentos de pesquisa, foram usados um teste e um diário de campo, para anotação das observações das atividades desenvolvidas pelos alunos durante a aplicação da intervenção de ensino.

O teste teve como objetivo diagnosticar o que os alunos sabem a respeito dos conteúdos abordados. É importante destacar que os estudantes já tinham estudado esses conteúdos antes do inicio da pesquisa, por meio de aulas sob abordagem tradicional, com explicações da professora-pesquisadora e com a resolução de exercícios propostos em livros didáticos.

O diário de campo é uma maneira de documentar o processo de investigação que está sendo desenvolvido. Conforme Fiorentini e Lorenzato (2006, p. 119), é por esse instrumento de coleta de dados que "o pesquisador registra observações de fenômenos, faz descrições de pessoas e cenários, descreve episódios ou retrata diálogos". O relato deve ser feito o mais próximo possível do momento da observação, para que os detalhes não sejam perdidos.

O estudo foi desenvolvido em uma Escola Municipal localizada no município de Quevedos, Rio Grande do Sul. Os sujeitos da pesquisa foram 24 alunos da 6a série, do turno da manhã, com idade média de 12 anos. Foi escolhida a 6ạ série por ser aquela em que é estudada a resolução de problemas algébricos.

Os conteúdos abordados em aula foram: equações do $1^{\circ}$ grau com uma incógnita, sistemas de equações do $1^{\circ}$ grau com duas incógnitas e inequações do $1^{\circ}$ grau com uma incógnita. Após a primeira aula sobre equações, foi aplicado o teste; a seguir, constatadas as dificuldades nas resoluções das equações, foi aplicado um jogo sobre o assunto. Da mesma forma, após as 
aulas sobre cada um dos outros conteúdos, foi empregado um jogo que abordasse as dificuldades apresentadas.

Os dados obtidos a partir das atividades desenvolvidas pelos alunos foram analisados em duas etapas:

a) foram inicialmente definidas as categorias de respostas ao teste e essa classificação foi baseada nos seguintes critérios: uma resposta é considerada correta se o aluno executou procedimentos que atendem às definições e propriedades das operações com racionais, ensinadas no Ensino Fundamental. Uma resposta é considerada parcialmente correta se as estratégias de resolução são encaminhadas de forma adequada, mas algum procedimento executado está em desacordo com as definições ou propriedades das operações. Uma resposta é considerada incorreta se estratégias e procedimentos são inadequados.

b) para analisar as observações das atividades desenvolvidas pelos alunos durante a aplicação dos jogos, após cada aula foram registrados, no diário de campo, os comportamentos dos alunos nos trabalhos individuais ou em duplas, bem como as soluções apresentadas por eles aos desafios propostos, para verificar se houve modificação das respostas em relação ao teste.

\section{Apresentação dos resultados}

O teste foi realizado individualmente, sem consulta ao material e foi composto por 12 equações do 1 o grau, divididas em grupos. A partir de dificuldades ou erros já encontrados em experiências de sala de aula da pesquisadora, bem como de ideias apresentadas em Freitas (2002), foram propostos os tipos de equação a seguir indicados.

a) Equações do tipo $a x=b^{1}$ :

2) $48 x=12$ e 4) $35 x=-105$

b) Equações do tipo $a x+b=c$ ou $b+a x=c$ :

1) $x-7=36 \quad$, 3) $10+x=7$ e 11) $x+7=36$

c) Equações do tipo $a x \pm b=c x \pm d$ :

\footnotetext{
${ }^{1}$ A numeração indicada é aquela com que a equação foi apresentada no teste.
} 
5) $3 x-2=4 x-7$ e 9$) 3 x-2=4 x-7$

d) Uma equação do tipo $a x \pm b=c x \pm d x \pm e$ :

6) $5 x+4=3 x-2 x+2$

e) Equações do tipo $b(a x+c)+d(e x+f)=g$ ou $a x \pm b(c x+d)=e$ :

8) $2(x-5)+4(x-1)=0$ e 12) $9 x-3(2 x+2)=15$

f) Uma equação do tipo $\frac{a x}{b} \pm c=\frac{d x}{e} \pm f$ :

7) $\frac{x}{4}+7=\frac{x}{2}+5$

g) Uma equação do tipo $\frac{a x \pm c}{b} \pm \frac{d \pm e x}{f}=g \pm \frac{h x-i}{j}$ :

10) $\frac{x+2}{2}-\frac{5-x}{2}=1+\frac{2 x-1}{3}$

Durante a realização do teste, os alunos não pediram explicações em relação à resolução das equações, mas em relação aos cálculos com números inteiros, mostrando dificuldades quanto às operações elementares.

Após a correção do teste, foram construídos os seguintes quadros, nos quais foram indicados o número $(\mathrm{N})$ de soluções corretas, parcialmente corretas, incorretas ou em branco, de cada equação, bem como o percentual correspondente.

\begin{tabular}{|l|c|c|c|c|c|c|c|c|c|c|c|c|}
\hline \multirow{2}{*}{$\begin{array}{l}\text { Soluções das } \\
\text { equações }\end{array}$} & \multicolumn{2}{|c|}{1} & \multicolumn{2}{|c|}{2} & \multicolumn{2}{|c|}{3} & \multicolumn{2}{|c|}{4} & \multicolumn{2}{|c|}{5} & \multicolumn{2}{c|}{6} \\
\cline { 2 - 14 } & N. & $\%$ & N. & $\%$ & N. & $\%$ & N. & $\%$ & N. & $\%$ & N. & $\%$ \\
\hline Correta & 7 & 41 & 5 & 29 & 8 & 47 & 8 & 47 & 9 & 53 & 9 & 53 \\
\hline $\begin{array}{l}\text { Parcialmente } \\
\text { Correta }\end{array}$ & 1 & 6 & 5 & 29 & 3 & 18 & 1 & 6 & 3 & 18 & 5 & 29 \\
\hline $\begin{array}{l}\text { Incorreta } \\
\text { Nãyo } \\
\text { respondeu }\end{array}$ & 1 & 47 & 6 & 35 & 4 & 24 & 7 & 41 & 5 & 29 & 3 & 18 \\
\hline \begin{tabular}{l} 
TOTAL \\
\hline
\end{tabular} & 17 & 100 & 17 & 100 & 17 & 100 & 17 & 100 & 17 & 100 & 17 & 100 \\
\hline
\end{tabular}

Quadro 1 - Distribuição das respostas às equações de 1 a 6 


\begin{tabular}{|l|c|c|c|c|c|c|c|c|c|c|c|c|}
\hline \multirow{2}{*}{$\begin{array}{l}\text { Soluções das } \\
\text { equações }\end{array}$} & \multicolumn{2}{|c|}{7} & \multicolumn{2}{|c|}{8} & \multicolumn{2}{|c|}{9} & \multicolumn{2}{c|}{10} & \multicolumn{3}{c|}{11} & \multicolumn{2}{c|}{12} \\
\cline { 2 - 14 } & $\mathrm{N}$. & $\%$ & $\mathrm{~N}$. & $\%$ & $\mathrm{~N}$. & $\%$ & $\mathrm{~N}$. & $\%$ & $\mathrm{~N}$. & $\%$ & N. & $\%$ \\
\hline Correta & 4 & 24 & 7 & 41 & 8 & 47 & 3 & 18 & 8 & 47 & 2 & 12 \\
\hline $\begin{array}{l}\text { Parcialmente } \\
\text { Correta }\end{array}$ & 6 & 35 & 3 & 18 & 4 & 24 & 7 & 41 & 0 & 0 & 5 & 29 \\
\hline Incorreta & 6 & 35 & 5 & 29 & 5 & 29 & 3 & 18 & 5 & 29 & 7 & 41 \\
\hline $\begin{array}{l}\text { Não } \\
\text { respondeu }\end{array}$ & 1 & 6 & 2 & 12 & 0 & 0 & 4 & 24 & 4 & 24 & 3 & 18 \\
\hline \begin{tabular}{l} 
TOTAL \\
\hline
\end{tabular} & 17 & 100 & 17 & 100 & 17 & 100 & 17 & 100 & 17 & 100 & 17 & 100 \\
\hline
\end{tabular}

Quadro 2 - Distribuição das respostas às equações de 7 a 12

Observamos que na resolução da equação 2 , do tipo $a x=b$, o número de erros foi maior do que o de acertos; já na equações 4, que é do mesmo tipo, a situação se inverteu.

Em termos de erros cometidos na resolução da equação 2, a maior parte deles foi relacionada ao fato de passar o coeficiente de x para o segundo membro com sinal negativo, que mostra não terem sido atendidos os princípios aditivo e multiplicativo da igualdade. Um exemplo de resolução incorreta pode ser visto na resolução ilustrada na Figura $1^{1}$

$$
\begin{aligned}
& 48 x=12 \\
& 48 x+12 \\
& x=-48+12 \\
& x=-36
\end{aligned}
$$

Figura 1 - Exemplo de resolução da equação 2

Em relação às equações do tipo $a x+b=c$ ou $b+a x=c$ (equações 1,3 e 11), observamos que o número de acertos nas resoluções da equação 3 é igual ao número de acertos na 11. Já o número de erros nas resoluções da questão 1 é maior do que o número de erros nas duas outras. No entanto, todas as três equações são do mesmo tipo, mostrando que existem detalhes, em cada equação, que geram maiores dificuldades. Nesse caso, consideramos que o sinal negativo, no primeiro membro da equação 1 , pode ter dificultado sua solução pelos

${ }^{1}$ Optamos por digitar as soluções porque o escaneamento das respostas, escritas a lápis, não ficou legível. 
estudantes. Essa hipótese pode ser analisada em outra pesquisa, que aprofunde, especificamente, a resolução desse tipo de equação.

Quanto às resoluções das questões de número 5, 6 e 9, a maior parte dos erros está relacionada ao fato de, na transposição de um termo em $x$ do segundo membro para o primeiro, não ter sido trocado o sinal do coeficiente de $x$, como podemos observar na solução apresentada a seguir, na Figura 2. Destacamos, também, nesse exemplo, que a passagem do número 2, do lado esquerdo para o direito, foi efetuada corretamente, mas a troca de membro de $4 x$ não atendeu ao princípio aditivo da igualdade. É interessante notar que, apesar de serem iguais as equações 5 e 9, houve diferenças no número de soluções corretas e parcialmente corretas.

$$
\begin{gathered}
3 x-2=4 x-7 \\
3 x+4 x=-7+2 \\
7 x=-5 \\
x=-5 / 7
\end{gathered}
$$

Figura 2- Exemplo de resolução da equação 5

Na resolução da equação 7, dentre os erros cometidos destacam-se a inobservância da troca de sinal de algum termo ao passá-lo de um membro para o outro da equação, a cópia errada de números, bem como a forma como os alunos tentaram eliminar os denominadores, como podemos ver nas soluções das Figuras 3 e 4, a seguir indicadas.

$$
\begin{aligned}
x / 4+7 & =x / 2+5 \\
4 . x / 4+4 .(+7) & =4 \cdot^{x} / 2+6 .(+5) \\
4 x / 4+28 / 1 & =4 x / 2+30 / 1 \\
1 x+28 & =2 x+30 \\
1 x+2 x & =+30-28 \\
3 x & =+2 \\
x= & +2 /+3
\end{aligned}
$$

Figura 3 -Exemplo de resolução da equação 7 


$$
\begin{gathered}
x / 4+7=x / 2+5 \\
4 x / 4+7=4 x / 2 \\
1 x+7=2 x \\
1 x-2 x=-7 \\
-1 x=-7 \\
x=-7 /-1
\end{gathered}
$$

Figura 4 - Outro exemplo de resolução da equação 7

Quanto às resoluções das equações 8 e 12 , do tipo $b(a x+c)+d(e x+f)=g$ ou $a x \pm b(c x+d)=e$, apesar de serem do mesmo tipo, verificamos que o número de acertos na resolução da equação 8 é maior do que na resolução da 12. Em termos de erros cometidos, a maior parte deles está relacionada à aplicação equivocada da propriedade distributiva da multiplicação, como podemos ver na solução representada na Figura 5:

$$
\begin{gathered}
9 x-3(2 x+2)=15 \\
9 x-3.2 x-3(+2)=3.15 \\
9 x-6 x-6=-5 \\
9 x-6 x=-5+6 \\
3 x=+1 \\
x=\frac{+1}{3}
\end{gathered}
$$

Figura 5 - Exemplo de resolução da questão 12

Na resolução da equação 10, apenas três alunos erraram, a maioria deles acertou total ou parcialmente. Essa equação envolvia todos os procedimentos utilizados, em parte, nas outras: determinar o mínimo múltiplo comum dos denominadores; aplicar a propriedade distributiva; fazer a transposição de termos de um membro para o outro, para em seguida isolar a variável $x$ no primeiro membro e encontrar a solução. Porém, apesar de envolver todas essas operações e propriedades, a equação 10 teve mais acertos, em sua resolução, do que outras equações mais simples. 


\section{Os jogos confeccionados e um exemplo de aplicação}

Face aos erros encontrados, consideramos que a confecção dos jogos deveria levar em conta essas dificuldades, além de ser uma tentativa de retomar o conteúdo de forma lúdica, para auxiliar os estudantes na sua compreensão.

Para o trabalho com os alunos, foram escolhidos e confeccionados três jogos: o "Quebracabeça triangular", o "Quarteto das equações" e o "Vira-e-confere".

O "Quebra-cabeça triangular" (CURY, 1995) consiste em um tabuleiro na forma de um triângulo equilátero, cujo interior é dividido em nove triângulos equiláteros menores. Para confeccionar o jogo, são utilizadas folhas de diferentes cores de papel cartão, folhas de ofício e papel contact.

Os alunos recebem o tabuleiro juntamente com os nove triângulos menores, de cores diferentes; na face de cada triângulo, sobre seus lados, são coladas três tiras de papel, nas quais são apresentados, respectivamente, três sistemas de equações (ou soluções de sistemas de equações). Aproveitando a moldura do tabuleiro, é possível propor dezoito sistemas de equações e suas respectivas soluções. O aluno deve resolver cada sistema e, encontrada a solução, deve encaixar o triângulo que tem a solução do sistema, de forma que fique adjacente ao outro em que há o sistema correspondente. Como os triângulos pequenos são de cores diferentes, o aluno vai formar uma sequência de cores que irá auxiliá-lo (e ao professor) no momento de fazer a correção do seu quebra-cabeça.

O "Quarteto das equações" (CURY; KONZEN, 2007) é um baralho com 36 cartas, constituído de nove quartetos, nomeados com letras, de A até I. As cartas são confeccionadas com folhas de papel cartão, folhas de oficio e papel contact.

Em cada quarteto, há uma equação, um sistema de equações e duas inequações, uma das sentenças já com a solução e as outras três em aberto. Um exemplo de carta é apresentado na Figura 6. As cartas são embaralhadas e distribuídas para três ou quatro jogadores. Se algum jogador notar que já tem um quarteto formado, ele o coloca de lado.

Escolhe-se um jogador para iniciar o jogo. Este tem, por exemplo, a carta A1, que já está com a resposta; pede, então, aos parceiros, a carta A2. Se um colega se manifesta afirmando que tem a carta, então quem fez a pergunta deve responder corretamente à questão proposta na carta $\mathrm{A} 2$ e o outro deve lhe entregar esta carta. O primeiro jogador continua perguntando pelas outras cartas que Ihe faltam, do quarteto A. Quando errar a resposta, o colega a quem ele perguntou continuará o jogo, da mesma forma. $\mathrm{O}$ jogo termina quando todos os quartetos forem formados. 


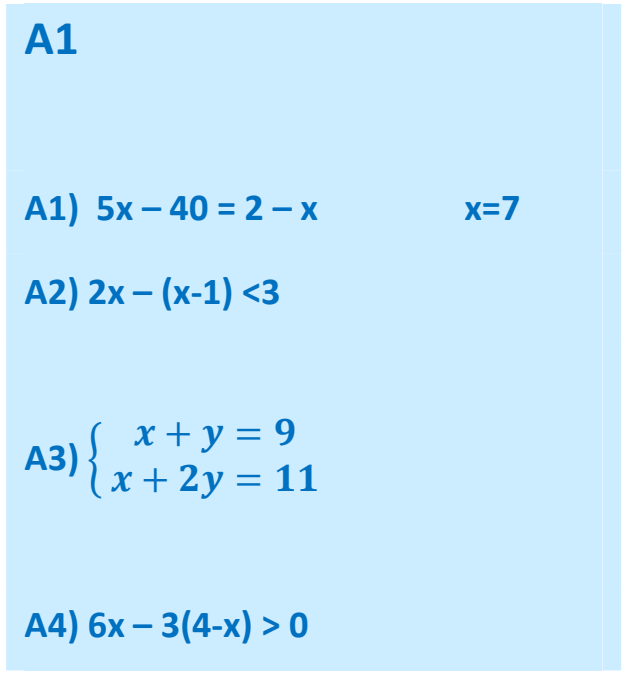

Figura 6 - Carta do jogo "Quarteto das equações"

O "Vira-e-Confere" consiste de uma cartela, confeccionada em material rígido, em cuja ponta é inserido um barbante com um nó, conforme se vê na Figura 7. No caso da experiência aqui relatada, a cartela foi feita de isopor, coberta com EVA ${ }^{1}$, e o barbante foi substituído por uma fita.

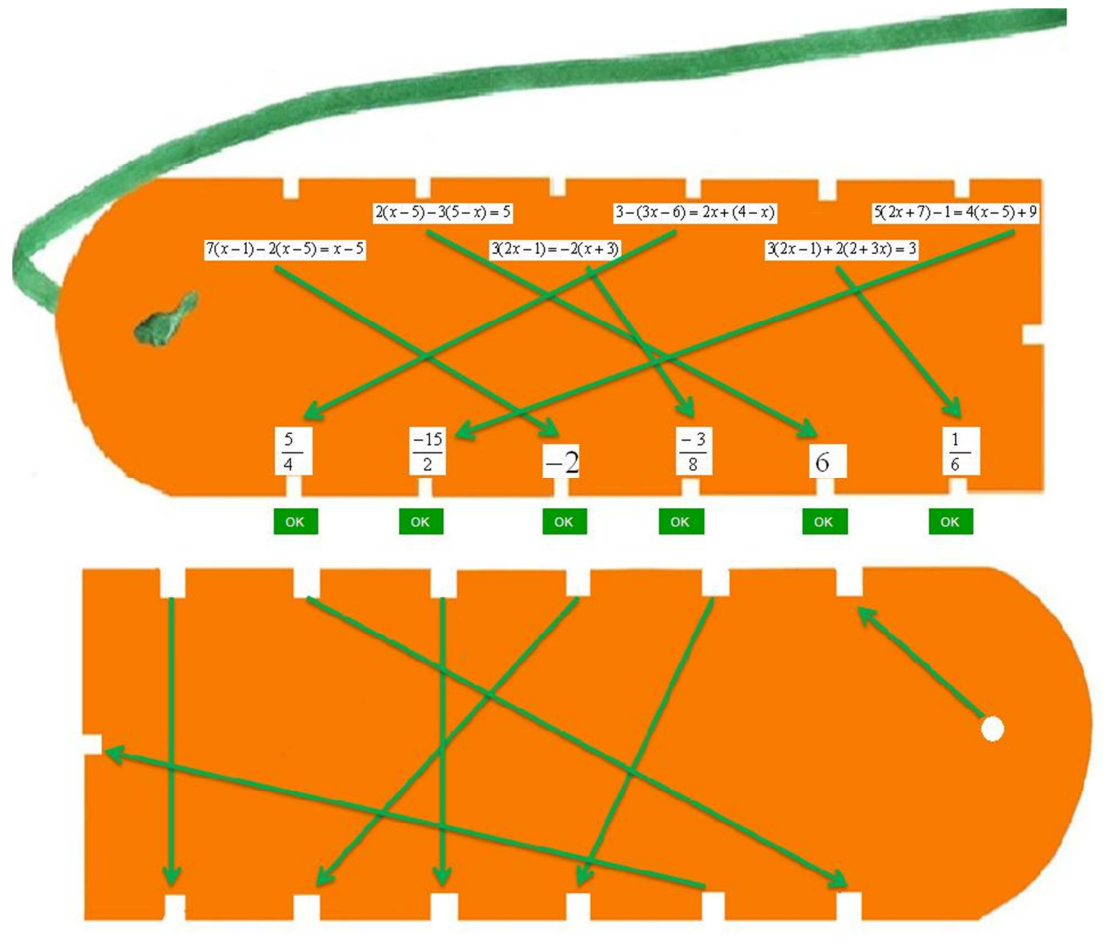

Figura 7-Frente e verso da cartela do jogo "Vira-e-Confere"

\footnotetext{
${ }^{1}$ Esse material é uma borracha composta de etil vinil acetato.
} 
Na cartela, há seis equações do 1ㅇ grau com suas respectivas respostas; essas não aparecem na mesma ordem em que as equações. Cada aluno recebe uma cartela, passa a fita sobre a primeira ranhura acima, à esquerda, abaixo da qual há uma equação. Em seguida, encontra a solução correspondente a essa equação, na parte inferior da cartela, e passa a fita por cima, até a ranhura correspondente à resposta. Após, passa a fita por baixo da cartela até a segunda ranhura e continua o processo até a última, depositando a fita na ranhura central à direita.Vira, então, a cartela e confere o percurso da fita: se coincidir com o desenho da cartela, o aluno acertou todas as questões, caso contrário pode tentar novamente.

Por restrições de espaço, optamos, neste artigo, por relatar apenas a aplicação do jogo "Vira-e-confere". Esse material manipulável foi proposto como jogo porque foram estipuladas regras. Os alunos jogaram em duplas, discutindo as soluções. Para que não houvesse possibilidade de olhar o verso da cartela antes de resolver as equações, foi colada uma folha de papel em branco sobre o desenho, que só era retirada pela professora ao final de cada rodada.

Se os jogadores acertassem as soluções de todas as equações, a dupla ganhava um ponto. A seguir, a professora colava novamente uma folha branca sobre o desenho apresentado no verso, as duplas trocavam as cartelas e era feita nova rodada. Ganhava o jogo a dupla que obtivesse mais pontos.

Ao iniciar a aula, os alunos foram separados em duplas e explicamos que iriam fazer um trabalho avaliativo, de uma maneira diferente da avaliação geralmente usada em suas aulas, por listas de exercícios resolvidos individualmente. Informamos que o material recebido era um jogo que envolvia o conteúdo de equações, apresentamos as regras e propusemos duas horas-aula para desenvolver a atividade. Solicitamos que trabalhassem em duplas e, se houvesse dúvidas, chamassem a professora.

No momento em que entregamos o jogo, a primeira pergunta foi sobre a existência do papel colado no verso da cartela. Explicamos que o papel seria retirado no final de cada rodada. Os alunos ficaram empolgados com o jogo e logo começaram a resolver as equações, semelhantes às que haviam sido resolvidas no teste.

No momento em que uma dupla completava sua cartela, os estudantes chamavam a professora e, juntos, retirávamos o papel que encobria o verso da cartela, verificando se o desenho determinado por eles coincidia com o da cartela. Feito isso, recebiam outra cartela e resolviam novas equações.

Anotamos as observações sobre o desempenho das duplas em um diário de campo. Nessa etapa, não houve a intenção de quantificar o número de acertos ou erros, mas de verificar se as duplas conseguiam resolver as equações, visto que, por fazer a observação ao mesmo tempo em que atendia os alunos, nem sempre era possível, à professora, determinar o número exato de acertos ou os tipos de erros cometidos. 
Pudemos observar que a realização da atividade em dupla ajudou muito alguns alunos na compreensão da resolução das equações, pois a linguagem que o colega utilizava para explicar era mais coloquial, mais simples que a da professora, quando explicava o mesmo assunto.

Ao contrário do que aconteceu no teste, os alunos não tiveram dúvidas quanto aos cálculos das operações elementares; talvez por estarem trabalhando em duplas, quando surgia uma dúvida, era discutida entre eles.

Algumas dificuldades apresentadas pelas duplas na resolução das equações foram relacionadas à transposição de um termo de um membro para outro. Outro erro cometido por algumas duplas foi de somar ou subtrair o coeficiente de $\mathrm{x}$ com um termo independente em um dos membros da equação. Esse erro já havia sido cometido pelos mesmos alunos na realização do teste.

Em relação aos procedimentos utilizados para resolver as equações, a maioria dos alunos mostrou tê-los compreendido a partir das aulas expositivas, mesmo nas equações que envolviam parênteses ou frações. Suas dificuldades relacionavam-se, em geral, aos problemas já indicados, relacionados aos princípios aditivo e multiplicativo e às propriedades das operações. A maioria das duplas resolveu as equações sem solicitar ajuda, só chamando a professora para confirmar se o jeito de passar a fita na cartela estava correto.

\section{Considerações finais}

Ao concluir a pesquisa sobre o uso de jogos para superar dificuldades na resolução de equações, sistemas de equações e inequações, podemos tecer algumas considerações. Em primeiro lugar, notamos que, no momento em que era mencionado o uso de um jogo, a primeira reação dos alunos era de empolgação e de curiosidade. Durante a realização dos jogos, observamos que a concentração dos alunos em resolver as atividades propostas era bem maior do que a apresentada durante as aulas em que eram propostas listas de exercícios.

Essa constatação vem ao encontro das observações de alguns autores que trabalharam com jogos em suas aulas. Lara (2003) destaca que, por meio de jogos, é possível desenvolvermos no aluno, além de habilidades matemáticas, sua concentração, sua curiosidade, a consciência de grupo, o coleguismo, o companheirismo, a autoconfiança e a autoestima.

Em sua dissertação, Silva (2004) também constatou que as aulas de Matemática deixaram de ser o "bicho-papão" da escola e passaram a ser aguardadas com ansiedade pelas crianças, que trabalharam mais pelo prazer da descoberta ou da vitória do que pela obrigação de realizar as tarefas, que, afinal, deixaram de ser tarefas para se tornarem brincadeiras. 
Souza (2006) percebeu que a participação dos alunos era cada vez maior e melhor, sempre que era utilizado algum jogo pedagógico, e que os estudantes, desafiados pelos jogos, demonstravam ansiedade para iniciar as atividades propostas. Além disso, a autora considera que, por meio dos jogos, os alunos pensam, investigam, buscam soluções e constroem suas próprias ações, o que estimula sua autonomia. Souza (2006) comprovou, em suas experiências, que os estudantes, ao terem oportunidade de pensar para realizar as jogadas, também corrigem seus próprios erros.

Durante o período em que ocorreram as aulas com os jogos aplicados na pesquisa aqui parcialmente relatada, foi possível verificar uma mudança na rotina das aulas de Matemática, pois a professora-pesquisadora não fazia uso apenas do quadro negro e do giz e os alunos, do caderno e do lápis; os estudantes não sentavam somente em filas e foi notado um maior interesse em sanar suas dúvidas em relação ao conteúdo, tendo em vista que precisavam saber os conceitos para poder jogar, o que não ocorria com frequência durante as aulas que antecederam o período da aplicação dos jogos.

Também foi possível notar que os jogos realizados em duplas ou em grupos contribuíram para despertar nos alunos o sentimento de coleguismo, companheirismo, além de auxiliarem na sua aprendizagem, tendo em vista que a linguagem utilizada pelo outro colega para explicar o conteúdo é mais acessível que a linguagem usada pela professora. Borin (1995) também menciona que os jogos devem ser trabalhados com pelo menos dois jogadores, pois isso facilita a troca de informação, a colaboração e contribui para as deduções das estratégias entre os alunos participantes.

Em sua dissertação, Souza (2006) observou que os jogos também contribuíram para despertar nos alunos o interesse pelo trabalho em grupo, o que lhes ajudou a entender alguns assuntos ainda não compreendidos, e que, ao longo das atividades com jogos pedagógicos, foram revisados.

Porém, é necessário ter cuidado em relação à forma com que os grupos serão organizados, pois nesta pesquisa ocorreu, em certo momento, a formação de um grupo de alunos que apresentavam maiores dificuldades em relação ao conteúdo. Nesse ponto, Smole, Pessoa, Diniz e Ishihara (2008) destacam que a organização dos grupos pode ser feita pelo professor de modo que os alunos com mais facilidade em jogar fiquem juntos com outros que precisam de ajuda. $\mathrm{Ou}$ ainda, podem ser formados grupos de alunos com compreensão semelhante do jogo ou da Matemática nele envolvida, deixando que esses estudantes joguem sozinhos, enquanto o professor acompanha aqueles que precisam de uma maior intervenção.

No período em que ocorreram os jogos realizados durante esta pesquisa, foi possível verificar os benefícios trazidos pelo seu uso pois, por meio desse recurso, foram identificados os alunos que apresentavam maiores dificuldades em relação aos conteúdos trabalhados; também 
foi possível constatar uma maior alegria, por parte dos estudantes, em ter aulas de Matemática, bem como em aprender os novos conteúdos, pois sabiam que, no final de cada capítulo, seria proposto um jogo.

Pelos resultados da aplicação dos jogos, consideramos que os objetivos da pesquisa foram alcançados, pois as dificuldades dos alunos na aprendizagem de equações, inequações e sistemas de equações foram analisadas, bem como a possibilidade de usar jogos para auxiliar os estudantes a superarem tais dificuldades.

Com a aplicação da experiência, houve possibilidade de ajudar os alunos a sanarem suas duvidas quanto aos conteúdos trabalhados, pois no momento em que jogavam, sentiam-se tão descontraídos que perdiam a vergonha de perguntar; além disso, o contato entre estudantes e professora era maior, pois era proporcionada mais atenção a eles durante a realização dos jogos.

A partir dessas considerações, trazemos então, como sugestão para outros professores de Matemática, a análise das dificuldades apresentadas pelos estudantes em algum conteúdo, em especial os relacionados à Álgebra do Ensino Fundamental, base para a maior parte dos tópicos estudados nos níveis seguintes. Também, a partir dessas dificuldades, sugerimos o uso de jogos para superá-las.

\section{Referências}

Borin, J. Jogos e Resolução de Problemas: uma estratégia para as Aulas de Matemática. São Paulo: IME-USP, 1995.

Cury, H. N. Quebra-cabeça triangular: jogo que trabalha com várias possibilidades. Revista do Professor, v. 11, n. 41, p. 22-22, jan. /mar. 1995.

Cury, H. N.; Konzen, B. Uma aplicação de jogos na análise de erros em educação matemática.

REVEMAT, v. 2.6, p. 107-117, 2007.

Damasco, F. C. Equações de 10 grau: uma experiência utilizando engenharia didática. 2008.

Dissertação (Mestrado em Ensino de Ciências e Matemática) - Universidade Luterana do Brasil, Canoas, 2008.

Fiorentini, D.; Lorenzato, S. Investigação em educação matemática: percursos teóricos e metodológicos. Campinas: Autores Associados, 2006.

Flemming, D. M.; Mello, A. C. C. de. Criatividade e Jogos Didáticos. 21a ed. São José: Saint Germain, 2003. 
Freitas, M. A. de. Equações do 10 grau: métodos de resolução e análise de erros no ensino médio. 2002. Dissertação (Mestrado em Educação Matemática) - Pontifícia Universidade Católica de São Paulo, São Paulo, 2002.

Jelinek, K. R. Jogos nas aulas de matemática: brincadeira ou aprendizagem? O que pensam os professores? 2005. Dissertação (Mestrado em Educação Matemática) - Pontifícia Universidade Católica do Rio Grande do Sul, Porto Alegre, 2005.

Lara, Isabel C.M. Jogando com a Matemática na Educação Infantil e Séries Iniciais. São Paulo: Rêspel, 2003.

Melo, J. J. de. Docência de inequações no ensino fundamental. 2007. Dissertação (Mestrado em Educação Matemática) - Pontifícia Universidade Católica de São Paulo, São Paulo, 2007.

Silva, E. D. da. Utilização de jogos e desafios no ensino de Matemática em turmas de sexta série do Ensino Fundamental. 2004. Dissertação (Mestrado em Ensino de Ciências e Matemática) Universidade Luterana do Brasil, Canoas, 2004.

Smole, K. S.; Pessoa, N.; Diniz, M. I.; Ishihara, C. Jogos de Matemática: de 1o e 3o ano. Porto Alegre: Artmed, 2008. (Cadernos do Mathema - Ensino Médio)

Soares, P. J. $\mathbf{O}$ jogo como recurso didático na apropriação dos números inteiros: uma experiência de sucesso. 2008. Dissertação (Mestrado Profissional em Ensino de Matemática) - Pontifícia Universidade Católica de São Paulo,São Paulo, 2008.

Souza, L. C. da C. Uma intervenção pedagógica com jogos nas aulas de reforço em matemática. 2006. Dissertação (Mestrado Profissionalizante em Ensino de Ciências e Matemática) Universidade Cruzeiro do Sul, São Paulo, 2006.

Angelita Uberti. Escola Municipal Olga Nunes da Silveira, Quevedos, RS. Mestre em Ensino de Matemática pela UNIFRA. angelitauberti@gmail.com Helena Noronha Cury. Centro Universitário Franciscano (UNIFRA), Santa Maria, RS. Mestrado Profissionalizante em Ensino de Física e de Matemática. Doutora em Educação pela Universidade Federal do Rio Grande do Sul. curyhn@unifra.br 